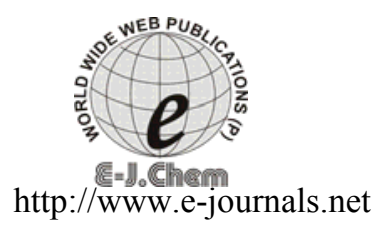

ISSN: 0973-4945; CODEN ECJHAO

E-Journal of Chemistry

2011, 8(S1), S271-S281

\title{
Copper(II) Complexes of Organophoshonic Acids-A Comparative Study
}

\author{
B.VENKATESWARA RAO* ${ }^{*}$ and D. M. PURI \\ *Department of Chemistry, Andhra Loyola College (Autonomous) \\ Vijayawada, Andhra Pradesh, India \\ Department of Chemistry, Kurukshetra University \\ Kurukshetra, 132119, India \\ bvrsss@yahooco.in
}

Received 24 December 2008; Revised 26 March 2009; Accepted 12 May 2011

\begin{abstract}
Polynuclear copper(II) derivatives of 1-hydroxyethylidenediphosphonic acid (HEDP), 1-aminoethylidenediphosphonic acid (AEDP, $\mathrm{H}_{4} \mathrm{~L}$ ), $\alpha$ aminobenzylidene diphosphonic acid (ABDP, $\mathrm{H}_{4} \mathrm{~L}$ ), 1-amino-2-carboxyethane1,1-diphosphonic acid (ACEDP, $\mathrm{H}_{5} \mathrm{~L}$ ), 1,3 diaminopropane-1,1,3,3-tetraphosphonic acid (DAPTP, $\mathrm{H}_{8} \mathrm{~L}$ ), Ethylenediamine- $N, N$ '-bis (dimethylmethylenephosphonic) acid (EDBDMPO, $\mathrm{H}_{4} \mathrm{~L}$ ), o-phenylene-diamine- $N, N^{\prime}$-bis (dimethylmethylenephosphonic) acid (PDBDMPO, $\mathrm{H}_{4} \mathrm{~L}$ ), diethylene triamine $-N, N, N^{\prime}, N^{\prime}, N^{\prime}$ ' $N$ '-penta (methylene phosphonic) acid (DETAPMPO, $\mathrm{H}_{10} \mathrm{~L}$ ) and diethylene triamine $-N, N$ '-bis (dimethyl methylene phosphonic) acid (DETBDMPO, $\mathrm{H}_{4} \mathrm{~L}$ ) have been prepared in aqueous medium. The general formula of derivatives from elemental analysis was found to be $\mathrm{Cu}_{2} \mathrm{~L} . \mathrm{XH}_{2} \mathrm{O}$ (in case of AEDP, ABDP, EDBDMPO, PDBDMPO, DETBDMPO), $\mathrm{Cu}_{5} \mathrm{~L}_{2} \cdot \mathrm{XH}_{2} \mathrm{O}$ (in case of ACEDP) $\mathrm{Cu}_{4} \mathrm{~L} . \mathrm{XH}_{2} \mathrm{O}, \mathrm{Cu}_{2} \mathrm{H}_{4} \mathrm{~L} . \mathrm{XH}_{2} \mathrm{O}$ (in case of DAPTP) and $\mathrm{Cu}_{5} \mathrm{~L}$. $\mathrm{XH}_{2} \mathrm{O}$ (in case of DETAPMPO). The electronic spectra have shown them to be six coordinated with slight distortion from octahedral geometry. Antiferromagnetism was inferred from magnetic moment data. Infrared spectral studies were carried out to determine coordination sites. EPR (Electron Paramagnetic Resonance) spectra that supports the presence of tetragonal distortion and antiferromagnetic behaviour, have also been studied.
\end{abstract}

Keywords: Organo phosphonic acids, Metal organophosphonates, Coordination sites, Six coordinate, Antiferromagnetism.

\section{Introduction}

Progress in many branches of science and engineering is more or less associated with the development of chemistry of coordination compounds. Coordination chemistry involves the synthesis of many newer polydentate ligands and their complexes with various metal ions. 
Polydentate nature of the ligands may be due to availability of lone pairs of electrons at donor sites. 1-Hydroxyethylidenediphosphonic acid (HEDP) has been known for the past many years. Synthesis of HEDP ${ }^{1-3}$ and its metal derivatives have been reported by some authors ${ }^{2}$. Cytochrome oxidase consists of heme and copper in the ratio of 1:1. Tryrosinases were first such enzymes in which copper was detected to be its essential constituent. Haemocyanin is a cupro protein found in mammals and functions as oxygen carrier.

+2 is the most common oxidation state for copper. Copper(II) adopts coordination number four, five and most commonly six. In the case of six coordinated complexes, regular octahedral coordination has been rarely observed because of the distortion due to JohnTeller effect, caused by the presence of ninth $3 \mathrm{~d}$ electron. This led to two short and four long bonds. Thus, in $\mathrm{CuCl}_{2}, \mathrm{CuBr}_{2}, \mathrm{CuF}_{2}$ and $\mathrm{CsCuCl}_{3}$, the $\mathrm{Cu}$ (II) ions are found in distorted octahedron ${ }^{4}$. $\left(\mathrm{NH}_{4}\right)_{2} \mathrm{CuCl}_{4}$ contains squashed ${ }^{5}$ tetrahedron $\mathrm{CuX}_{4}^{-2}$. Tetrahedral complexes of the type $\mathrm{Cu}\left(\mathrm{Ph}_{3} \mathrm{PO}\right)_{2} \mathrm{X}_{2}$ are also known ${ }^{6}$. $\mathrm{Cu}$ (II) forms complex with EDTA, which has been used as a complexometric titrating agent ${ }^{7}$. In $\mathrm{Cu} \mathrm{Cl}_{5}^{-3}$ and $\mathrm{Cu}$ (terpy) $\mathrm{Cl}_{2}, \mathrm{Cu}$ (II) is known to occur in penta-coordinated state. In the complex, $\mathrm{Cu}\left(\mathrm{NH}_{3}\right)_{4} \mathrm{SO}_{4} \cdot \mathrm{H}_{2} \mathrm{O}$, four nitrogen atoms are in square plane around copper(II) and the water molecule takes up the fifth coordinated position.

Majority of the copper(II) complexes are tetragonally distorted, as in an octahedral field, the ground state term ${ }^{2} E_{g}$ is subjected to considerable Jahn teller distortion. For such complexes, a single absorption band was observed in the visible region near $16,000 \mathrm{~cm}^{-1}$ attributed to ${ }^{2} \mathrm{E}_{\mathrm{g}} \longleftarrow{ }^{2} \mathrm{~T}_{2 \mathrm{~g}}$ transition. The band is asymmetric because of splitting by a low symmetry ligand field component. The tetrahedral derivatives can be very easily distinguished from octahedral ones, as they do not absorb in 10,000-20,000 $\mathrm{cm}^{-1}$.

Aminoethylidenediphosphonic acid and $\alpha$-aminobenzylidenediphosphonic acid (ABDP) had a very strong herbicidal effect against barnard grass, mustard and tomato seedlings and had fungicidal properties. 1-Amino-2-carboxyethane -1, 1-diphosphonic acid (ACEDP) has been used as water softner, for flask cleaning or as additive for dyeing baths for textiles $^{8}$. An organophosphonic acid acts on a metal atom consisting of a labile linkage enabling it to remove the metal. Such property of alkylenebisnitrilodialkylphosphonic acids to form very stable complexes with bivalent copper, lead to the elimination of copper from the organism? .

EDBDMPO (ethylenediamine- $N, N^{\prime}$-bis (dimethylmethylenephosphonic)acid) and DETAPMPO(Diethylene triamine $-N, N, N$, $N$,,$N$ ' $N$ ''-penta (methylene phosphonic) acid) were more effective than DTPA (Diethylene triamine penta acetic acid) in reducing the uranium content in rat organs ${ }^{10}$.

Polyaminealkylphosphonic acids may be used as effective ligands for binding and eliminating uranium and its fission products from the body. From the survey of the literature about some organophosphonic acids and their metal derivatives, it is evident that except for the physicochemical and biological studies, very little work has been carried out on the synthetic and structural aspects of metal derivatives of organoaminophosphonic acids. In view of this, an attempt was made to study the reaction between organo amino polyphosphonic acids and metal salts in aqueous medium and to make a comparative study of their structures using different physicochemical techniques.

\section{Experimental}

All chemicals used were of AnalaR (Analytical Reagent) or reagent grade. 1-Aminoethylidene di-phosphonic acid (AEDP, $\left.\mathrm{H}_{4} \mathrm{~L}\right)$ was prepared by the reaction reported by ploger et al. ${ }^{11}$ 
by reacting acetamide with phosphorus trichloride and diethylphosphite in 1:3:1 molar ratio. $\alpha$-Amino benzylidene diphosphonic acid (ABDP, $\mathrm{H}_{4} \mathrm{~L}$ ), 1-amino-2-carboxyethane-1, 1-diphosphonic acid (ACEDP, $\mathrm{H}_{5} \mathrm{~L}$ ) and 1,3 diaminopropane-1,1,3,3-tetraphosphonic acid (DAPTP, $\mathrm{H}_{8} \mathrm{~L}$ ) were prepared through the method used by Lerch and Kottler ${ }^{12}$. Ethylenediamine- $N, N^{\prime}$-bis (dimethylmethylenephosphonic) acid (EDBDMPO, $\mathrm{H}_{4} \mathrm{~L}$ ) and $o$-phenylenediamine- $N, N$ '-bis(dimethylmethylenephosphonic) acid (PDBDMPO, $\mathrm{H}_{4} \mathrm{~L}$ ) were prepared through the method reported by Kabachnik et $a l^{12}$. Diethylene triamine $-N, N, N^{\prime}, N^{\prime}, N^{\prime}$ ' $N$ '-penta (methylene phosphonic) acid (DETAPMPO, $\mathrm{H}_{10} \mathrm{~L}$ ) has been prepared by the method used by Peck and Hudson. Diethylenetriamine- $N, N$ ''-bis (dimethylmethylenephosphonic) acid (DETBDMPO, $\mathrm{H}_{4} \mathrm{~L}$ ) have been prepared in aqueous medium by the method reported by Medved et al. ${ }^{13}$.

\section{Preparative method for the complexes}

\section{Reaction between AEDP and copper(II) acetate}

To 0.001 moles $(0.205 \mathrm{~g})$ of ligand solution 0.002 mole of $0.399 \mathrm{~g}$ of cupric acetate solution was added followed by $20 \mathrm{~mL}$ of 0.004 mole of $\mathrm{NaOH}$ solution. Light blue precipitate so formed was filtered, washed several times with hot water, aqueous acetone and finally dried with acetone $(90 \%)$. It was then dried on water bath. (Yield= $83 \%$ ).

\section{General method of preparation of metal complexes}

The above procedure may be taken as a general procedure for remaining complexes. In case of reaction between ABDP and copper(II) acetate, the procedure used for this is same as above but $\mathrm{NaOH}$ was not added. In this case, the yield was improved by the addition of acetone to the reaction mixture. (Yield $=79 \%$ ). In case of reaction between ACEDP and copper(II) acetate, the procedure used for this is same as above but $\mathrm{Na}_{2} \mathrm{CO}_{3}$ was added. In this case, the yield was improved by the addition of acetone to the reaction mixture. (Yield $=65 \%$ ). In case of reaction between DAPTP and copper(II) acetate in 1:4 molar ratio, the procedure used for this is same as above but $\mathrm{Na}_{2} \mathrm{CO}_{3}$ was added. (Yield=89\%).In case of reaction between DAPTP and copper(II) acetate in 1:2 molar ratio, the procedure used for this is same as above but $\mathrm{NaOH}$ was not added .(Yield $=85 \%$ ). In case of the reaction between EDBDMPO and copper(II) acetate (yield, 79\%), the procedure used for this is same .In case of the reaction between DETAPMPO and copper(II) acetate, $\mathrm{NaOH}$ or $\mathrm{Na}_{2} \mathrm{CO}_{3}$ was not used. However, in case of the reaction between DETBDMPO and copper(II) acetate, $\mathrm{NaOH}$ was used.

Carbon and hydrogen in case of ligands were estimated by means of semi-micro analyzer, LG, VEB Laborgerate and Orthopadic Leipzig. Nitrogen was estimated by Duma's method. Metal and phosphorus contents were determined by standard procedures ${ }^{14}$. Chromium(III) and iron(III) were estimated gravimetrically as $\mathrm{BaCrO}_{4}$ and iron Oxinate respectively.

\section{Physical measurements}

Diffused transmittance spectra were run on DMR-21 spectrophotometer in 200-2000 nm (50,000-5000 $\left.\mathrm{cm}^{-1}\right)$ region, diffused reflectance spectra were run on Cary 2390 spectrophotometer in $200-1800 \mathrm{~nm}\left(50,000-5555.5 \mathrm{~cm}^{-1}\right)$ region at RSIC (SAIF), Madras India. EPR spectra of the solid copper complexes were recorded at RSIC (SAIF), Madras using Varian R-4(x-band) spectrophotometer, which was operated at 9.5 GHZ. DPPH was used as the $\mathrm{g}$ marker. Magnetic susceptibility measurements were carried out using a princeton applied research model 155 vibrating sample magnetometer incorporating a 
digital read out. The electromagnet was fed from a polytronic constant current regulator (Type CP 200). A pure nickel pellet was used as calibrant, crosschecking against $\mathrm{Hg}$ [Co (CNS) $\left.{ }_{4}\right]$. The instruments and methods used for the remainder of the analyses were the same as described earlier ${ }^{15-17}$. Thermal analysis of the compounds was done in the atmosphere of air at national chemical laboratory, Pune. The specimens were heated at the rate of $10{ }^{\circ} \mathrm{C} / \mathrm{min}$. in $20-1000{ }^{\circ} \mathrm{C}$ range and heated alumina was used as standard.

\section{Results and Discussion}

\section{Infrared spectra}

In the infrared spectra of the free ligand, a characteristic band is observed at $1190 \mathrm{~cm}^{-1}$ (AEDP), $1230 \mathrm{~cm}^{-1}$ (ABDP), $1160 \mathrm{~cm}^{-1}$ (ACEDP), $1160 \mathrm{~cm}^{-1}$ (DAPTP), $1220 \mathrm{~cm}^{-1}$ (EDBDMPO), $1210 \mathrm{~cm}^{-1}$ (PDBDMPO), $1240 \mathrm{~cm}^{-1}$ DETAPMPO) and $1190 \mathrm{~cm}^{-1}$ (DETBDMPO), which may be due to the phosphoryl $\mathrm{v}(\mathrm{P}=\mathrm{O})$ vibrations. Corbridge and Bellamy have assigned $1320-1200 \mathrm{~cm}^{-1}$ region for $\mathrm{v}(\mathrm{P}=\mathrm{O})$ stretching frequency from the survey of a large number of phosphorous compounds having free phosphoryl group. Stretching vibrations of phosphoryl group in case of metal derivatives have been observed at $1110-1155 \mathrm{~cm}^{-1}$. The displacement of the band by $45-90 \mathrm{~cm}^{-1}$ towards lower region has been attributed to the formation of coordination bond between phosphoryl oxygen and metal ion. Such observations have also been made in case of polyaminopolyphosphonic acids reported earlier from these laboratories ${ }^{15,16}$ and are also in agreement with the observations of khramov et al. ${ }^{18}$. The two more bands at around 1130 and around $1020 \mathrm{~cm}^{-1}$ were observed in all the free ligands correspond to $\mathrm{V}_{\mathrm{as}} \mathrm{PO}_{2}$ and $\mathrm{V}_{\mathrm{s}} \mathrm{PO}_{2}$ vibrations in $\mathrm{HPO}_{3}{ }^{-}$group In addition, $\mathrm{V}_{\text {as }} \mathrm{P}-\mathrm{OH}$ and $\mathrm{V}_{\mathrm{s}} \mathrm{P}-\mathrm{OH}$ bands, corresponding to $\mathrm{P}-(\mathrm{OH})_{2}$ also appeared at around 1000 and around $940 \mathrm{~cm}^{-1}$. In metal derivatives, the asymmetric and symmetric mode of stretching vibration of $\mathrm{PO}_{3}^{-2}$ group appeared at $1070-1020$ and $1000-900 \mathrm{~cm}^{-1}$ ranges, respectively and splitting of these bands was observed. Such splitting is expected in view of the covalent character of $\mathrm{M}-\mathrm{O}$ bond due to lowering of the symmetry of $\mathrm{PO}_{3}$ group.

In case of AEDP and ABDP the stretching and bending mode of $-\mathrm{NH}_{3}{ }^{+}$group has been observed at $3400 \mathrm{~cm}^{-1}$ and $1580 \mathrm{~cm}^{-1}$ respectively. The bands at $3400 \mathrm{~cm}^{-1}$ and $3200 \mathrm{~cm}^{-1}$ may be due to the presence of $\mathrm{OH} / \mathrm{NH}$ groups. Two more bands at $3060 \mathrm{~cm}^{-1}$ and $1450 \mathrm{~cm}^{-1}$ were present in ABDP and may be assigned due to aromatic grouping ${ }^{19}$. In the infrared spectra of complexes the rocking and wagging vibrations appeared in the regions 880-860 $\mathrm{cm}^{-1}$ and $750-710 \mathrm{~cm}^{-1}$ suggesting the presence of coordinated water ${ }^{19-21}$.

A medium sharp band due to $\mathrm{V}_{\text {asym }}\left(\mathrm{COO}^{-}\right)$group observed at $1660 \mathrm{~cm}^{-1}$ in the free ligand (ACEDP), shifted to lower frequency $\left(1645-1630 \mathrm{~cm}^{-1}\right)$ in all the complexes indicating that the carboxylic group is coordinated ${ }^{22,23}$. to the metal atom of the same or another molecule. Another band found at $1300 \mathrm{~cm}^{-1}$ in the free ligand (ACEDP) spectrum was due to the presence of $\mathrm{V}_{\text {asy }}\left(\mathrm{COO}^{-}\right)$vibration. In the metal complexes, this band was found shifted to $1430-1400 \mathrm{~cm}^{-1}$, indicating the involvement of the carboxylic group in bond formation with the metal ${ }^{24}$. The lowering of $\mathrm{v}_{\text {asym }}\left(\mathrm{COO}^{-}\right.$) (mainly due to $\mathrm{V}(\mathrm{C}=\mathrm{O})$ of the ( $\mathrm{COOH}$ group $)$ ) and the difference $\Delta=\mathrm{V}_{\text {asym }}\left(\mathrm{COO}^{-}\right)-\mathrm{V}_{\text {sym }}\left(\mathrm{COO}^{-}\right)$is approximately equal to $200 \mathrm{~cm}^{-1}$, which clearly suggested the coordinations of $\mathrm{V}(\mathrm{C}=\mathrm{O})$ moiety to the metal atom $^{24}$.

The bands at 1090 and $1040 \mathrm{~cm}^{-1}$ were assigned to $\mathrm{v}_{\mathrm{as}}\left(\mathrm{PO}_{2}\right)$ and $\mathrm{v}_{\mathrm{s}}\left(\mathrm{PO}_{2}\right)$ vibrations in the group $\mathrm{HPO}_{3}^{-}$. Two more bands were observed at 990 and $940 \mathrm{~cm}^{-1}$ which may be due to $\mathrm{v}_{\mathrm{as}} \mathrm{P}-(\mathrm{OH})_{2}$ and $\mathrm{v}_{\mathrm{s}} \mathrm{P}-(\mathrm{OH})_{2}$ vibrations of $\mathrm{PO}_{3} \mathrm{H}_{2}$ group in case of DETBDMPO. The above observations suggested that the ligand $\left(\mathrm{H}_{4} \mathrm{~L} .2 \mathrm{H}_{2} \mathrm{O}\right)$ has betaine -like structure (I and II) also. 


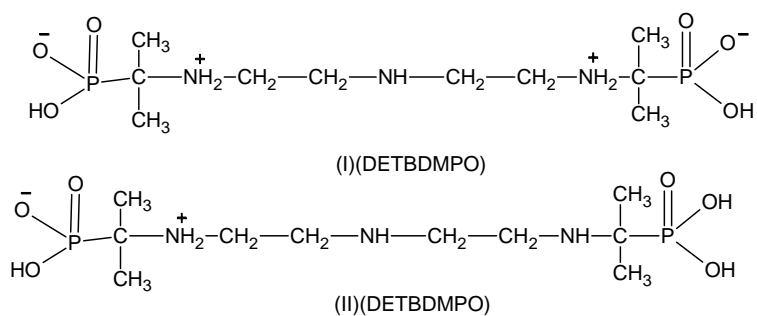

$\mathrm{NH}_{2}^{+}$group often gives two broad unresolved bands in the region of $3000-2750 \mathrm{~cm}^{-1}$. In the infrared spectrum of free DETBDMPO, there was a broad band in the region $3400-2600 \mathrm{~cm}^{-1}$ which may be due to masking of $\mathrm{v}\left(\mathrm{NH}_{2}{ }^{+}\right)$bands by broad $\mathrm{v}(\mathrm{OH})$ band. A weak Band at $1620 \mathrm{~cm}^{-1}$ has been assigned to $\ddot{0}(\mathrm{~N}-\mathrm{H})^{19,25}$. Two bands were present in the region of $450-410 \mathrm{~cm}^{-1}$ and $330-300 \mathrm{~cm}^{-1}$ in far infrared spectra of complexes and assigned to M-O and $\mathrm{M}-\mathrm{N}$ linkages respectively.

\section{Electronic spectra}

There is one transition in the electronic spectrum of the copper(II) complex (copper(II)HEDP complex, $\mathrm{CuL} .2 \mathrm{H}_{2} \mathrm{O}$ ) at $13,330 \mathrm{~cm}^{-1}$ that suggests a distorted octahedral structure of the complex. Another band at $16,310 \mathrm{~cm}^{-1}$ has also been observed.

$\mathrm{Cu}_{2}$ (AEDP). $2 \mathrm{H}_{2} \mathrm{O}$ gave a single broad band in the visible region at $13,160 \mathrm{~cm}^{-1}$ and has been attributed to ${ }^{2} \mathrm{~T}_{2 \mathrm{~g}} \longleftarrow{ }^{2} \mathrm{E}_{\mathrm{g}}$ transition in six-coordinated geometry ${ }^{26}$. The broadness of the band may be due to Jahn-Teller distortion. These observations suggest that the complexes have distorted octahedral structures ${ }^{18}$.

The light blue coloured $\mathrm{Cu}_{2}$ (L). $2 \mathrm{H}_{2} \mathrm{O}$ (ABDP) when subjected to diffused transmittance spectrum showed a single band at $13,360 \mathrm{~cm}^{-1}$ in the visible region. This is typical of hexa co-coordinated species of copper(II) and was attributed to ${ }^{2} \mathrm{~T}_{2 \mathrm{~g}} \longleftarrow{ }^{2} \mathrm{E}_{\mathrm{g}}$ transition. The absence of any absorption below $10,000 \mathrm{~cm}^{-1}$ eliminates the possibility of tetrahedral stereochemistry for the complex ${ }^{27,28}$. Therefore, from the electronic spectrum tetragonally distorted octahedral geometry is inferred.

For copper(II)-ACEDP complex a band at $20,000 \mathrm{~cm}^{-1}$ has been attributed to the transition ${ }^{2} \mathrm{E}_{\mathrm{g}} \longleftarrow{ }^{2} \mathrm{~T}_{2 \mathrm{~g}}$, which is typical of $\mathrm{Cu}$ (II) ion in the tetragonally distorted octahedral environment ${ }^{29-31}$. Some authors have attributed this to a ligand field band ${ }^{31}$.

The diffused reflectance spectra of two copper complexes of DAPTP have been found to be 19,$050 ; 23,260 \mathrm{~cm}^{-1}$ (sh) and 18,$800 ; 22,220 \mathrm{~cm}^{-1}$ (sh) for $\mathrm{Cu}_{4}(\mathrm{~L}) \cdot 6 \mathrm{H}_{2} \mathrm{O}$ and $\mathrm{Cu}_{2} \mathrm{H}_{4}(\mathrm{~L}) \cdot 2 \mathrm{H}_{2} \mathrm{O}$ respectively which may be due to distorted octahedral geometry ${ }^{3 \mathrm{la}} .19,050 \mathrm{~cm}^{-1}$ for $\mathrm{Cu}_{4} \mathrm{~L} \cdot 6 \mathrm{H}_{2} \mathrm{O}$ and $18,800 \mathrm{~cm}^{-1}$ for $\mathrm{Cu}_{2} \mathrm{H}_{4} \mathrm{~L} \cdot 2 \mathrm{H}_{2} \mathrm{O}$ may be taken as $10 \mathrm{Dq}^{31 \mathrm{~b}}$. The bands observed at 23,260 and $22,220 \mathrm{~cm}^{-1}$ may be due too the presence of metal-metal interaction ${ }^{32,33}$ or they may be charge transfer bands. Agambere et $a l^{29}$ have observed only one d-d transition band in the region of $20,00-20,800 \mathrm{~cm}^{-1}$, which they assigned to ${ }^{2} \mathrm{E}_{\mathrm{g}} \longleftarrow{ }^{2} \mathrm{~T}_{2 \mathrm{~g}}$ transition for their $\mathrm{Cu}(\mathrm{II})$ complexes.

Copper(II) formed a light blue coloured complex with EDBDMPO. In its electronic spectrum, a single band was observed at $13,333 \mathrm{~cm}^{-1}$ and a distorted octahedral structure for this complex is proposed ${ }^{34}$. An additional weak band is observed at $23,530 \mathrm{~cm}^{-1}$. Some authors have attributed this to metal-metal interactions ${ }^{35,36}$.

There is a single transition in the electronic spectrum of $\mathrm{Cu}$ (II) PDBDMPO complex at $13,330 \mathrm{~cm}^{-1}$ and a distorted octahedral structure for the same is proposed ${ }^{34}$. Another band at $23,530 \mathrm{~cm}^{-1}$ has also been observed and can be attributed to metal-metal interactions ${ }^{36,37}$. 
In copper(II) DETAPMPO complex a band, observed at $21,050 \mathrm{~cm}^{-1}$ was assigned to ${ }^{2} \mathrm{~T}_{2 \mathrm{~g}} \longleftarrow{ }^{2} \mathrm{~T}_{2 \mathrm{~g}}$ transition for distorted octahedral or square planar environment. Another band at $29,410 \mathrm{~cm}^{-1}$ was attributed to metal-metal interactions. Two more bands were observed at $33,330 \mathrm{~cm}^{-1}$ and $34,480 \mathrm{~cm}^{-1}$ that may be charge transfer in nature from metal to ligand or ligand to metal interactions ${ }^{24}$.

The copper(II) DETBDMPO complex exhibited only a single band at $20,410 \mathrm{~cm}^{-1}$ in its diffused reflectance spectrum. This is consistent with distorted octahedral geometry.

\section{Magnetic moments (Table 1)}

Magnetic moment of copper(II) HEDP complex was 2.02 B.M., which is in agreement with $\mathrm{d}^{9}$ configuration. This value is a little higher than required for octahedral complexes. The magnetic moment value of 1.39B.M for copper(II) AEDP complex is lower than the expected value of 1.7-2.2 B.M range for $\mathrm{d}^{9}$ system. This subnormal magnetic moment value may be due to antiferromagnetism arising due to exchange interactions from either direct metal-metal interactions or super exchange via phosphonic bridges.

Table 1. Temperature dependent magnetic moment data of metal derivatives

\begin{tabular}{cccccc}
\hline $\mathrm{T}, \mathrm{K}$ & $\mathrm{F}$ & $\mathrm{B}$ eff, B.M. \\
\hline & $\mathrm{A}$ & $\mathrm{B}$ & $\mathrm{D}$ & $\mathrm{E}$ \\
296 & 1.37 & 0.92 & 1.42 & 1.251 & 1.04 \\
261 & 1.340 & 0.89 & 1.41 & 1.245 & 1.01 \\
213 & 1.290 & 0.88 & 1.37 & 1.236 & 0.98 \\
189 & 1.260 & 0.87 & 1.335 & 1.225 & 0.97 \\
165 & 1.240 & 0.838 & 1.327 & 1.213 & 0.92 \\
141 & 1.210 & 0.818 & 1.30 & 1.205 & 0.88 \\
117 & 1.180 & 0.808 & 1.24 & 1.19 & 0.85 \\
93 & 1.140 & 0.791 & 1.19 & 1.14 & 0.79 \\
77 & 1.070 & 0.736 & 1.13 & 1.11 & 0.77 \\
\hline
\end{tabular}

$A=\mathrm{Cu}_{2}\left(\mathrm{C}_{7} \mathrm{H}_{7} \mathrm{NO}_{6} \mathrm{P}_{2}\right) \cdot 2 \mathrm{H}_{2} \mathrm{O}[\mathrm{Cu}(\mathrm{II})-\mathrm{AEDPcomplex}], \mathrm{B}=\mathrm{Cu}_{5}(\mathrm{~L})_{2} 4 \mathrm{H}_{2} \mathrm{O}[\mathrm{Cu}(\mathrm{II})-\mathrm{ACEDPcomplex}], \mathrm{C}=\mathrm{Cu}_{2}(\mathrm{~L})$. $2 \mathrm{H}_{2} \mathrm{O}\left[\mathrm{Cu}(\mathrm{II})\right.$-EDBDMPOcomplex], $\mathrm{D}=\mathrm{Cu}_{2}(\mathrm{~L}) .2 \mathrm{H}_{2} \mathrm{O}\left[\mathrm{Cu}(\mathrm{II})\right.$-PDBDMPOcomplex], $\mathrm{E}=\mathrm{Cu}_{5}(\mathrm{~L}) 15 \mathrm{H}_{2} \mathrm{O}$ [Cu(II)-DETAPMPOcomplex]

Copper(II)-ABDP complex has the effective magnetic moment value of 1.32 B.M., which is lower than the magnetic moment value of 1.70-2.20 B.M range for $\mathrm{d}^{9}$ system. This shows the presence of some antiferromagnetism arising due either to direct metal-metal interaction or super exchange through the phosphonic bridges. The antifereromagnetism has been further confirmed based on magnetic moment values at different temperatures ( 77 $\mathrm{K}$ to $296 \mathrm{~K}$ ). The magnetic moment decreases with the decrease in temperature as expected for antiferromagnetic complexes. Graph of $1 / \chi^{\prime} \mathrm{M} v s$. temperature gave a straight line with a negative Weiss constant value $\left(\theta=-98^{0}\right)$. Kiriyama, Ibamoto and Metsuo ${ }^{38}$ have reported that in case of cupric formate tetrahydrate, the dimeric structure of the acetate is absent and a path for direct exchange between copper ions is not possible. However, according to them, the exchange does occur presumably by a super exchange mechanism inferred from the value of $\theta$ which is $-17^{0}$.

The magnetic moment value of 0.95 B.M. of copper(II)-ACEDP complex $\left(\mathrm{Cu}_{5}(\mathrm{~L})_{2} .4 \mathrm{H}_{2} \mathrm{O}\right)$ at $306 \mathrm{~K}$ was much lower than the normal value (1.7-2.2 B.M) for $\mathrm{d}^{9}$ species and may be due either to metal-metal interaction or super exchange. At $296 \mathrm{~K}$, the magnetic 
moment value was found to be 0.92 B.M, which further decreased to 0.69 B.M. with decrease in temperature to $77 \mathrm{~K}$. This is also expected for antiferromagnetic complexes ${ }^{39}$. Plotting the graph of $1 / \chi^{\prime} M v s$. temperature gave a straight line, a negative value of $\theta$ which is $-100^{\circ}$ was obtained.

The lower magnetic moment values (Copper (II)-DAPTP complex) (0.87B.M) for $\mathrm{Cu}_{4}(\mathrm{~L}) \cdot 6 \mathrm{H}_{2} \mathrm{O}$ and 1.6B.M for $\mathrm{Cu}_{2} \mathrm{H}_{4}(\mathrm{~L}) \cdot 2 \mathrm{H}_{2} \mathrm{O}$ showed the presence of antiferromagnetism arising either from metal-metal interaction or through super exchange via phosphonic acid bridges. The trend in the values of magnetic moment continued to be the same for all the metal complexes. The magnetic moment values for 2:1 and 4:1 metal: ligand(DAPTP) complexes showed the increasing antiferromagnetic exchange interaction with the increase in number of metal ions per molecule, suggesting more probability of metal -metal interactions.

The magnetic moment has been found to be 1.42 B.M for copper(II) EDBDMPO complex. This lowered magnetic moment value expected for $\mathrm{d}^{9}$ system(1.7-2.2 B.M) may be due to some antiferromagnetic exchange interactions arising from either metal-metal interactions via overlap of suitable metal orbitals or through super exchange resulting from the paramagnetic spin density transferred from one metal ion through the phosphonic acid groups to an adjacent metal ion. In this case, the possibility of metal-metal interactions may be further confirmed as shown by the presence of an additional band at $23,530 \mathrm{~cm}^{-1}$ in its electronic spectrum $^{37,40}$. A graph of $1 / \chi^{\prime} \mathrm{M}$ (on Y axis) vs. temperature (on X axis) was plotted. The magnetic moment decreases with the decrease in temperature as expected for antiferromagnetic complexes ${ }^{40 \mathrm{a}, 40 \mathrm{~b}}$. Curie-Weiss law is obeyed with the negative value of $\theta$, which is $-150^{\circ}$.

The magnetic moment of copper(II) PDBDMPO complex ( $\mu$ eff (B.M.)) was found to be 1.25 B.M. This is consistent with strong antiferromagnetic spin-spin interaction through molecular association. From the cryomagnetic data, a graph was plotted ( $1 / \chi^{\prime} \mathrm{M} v s$. temperature) from which Weiss- $\operatorname{constant}(\theta)$ value was calculated to be $-36^{0}$. This further confirms the presence of antiferromagnetic behavior of the complex ${ }^{41}$.

The magnetic moment $\mathrm{Cu}(\mathrm{II})$ DETAPMPO complex was found to be 1.04B.M. However, $\mu$ eff (B.M.) is less than that for isolated copper(II) ions and it decreases markedly with decreasing temperature. Graph of $1 / \chi^{\prime} \mathrm{M} v s$. temperature gave a negative value of $\theta$ $\left(-118^{0} \mathrm{C}\right)$

The magnetic moment of the copper(II) DETBDMPO complex has been found to be 1.5B.M. This shows the presence of antiferromagnetism due to the value being lower than the expected one.

\section{EPR spectral study}

The EPR spectrum of a powdered sample of copper(II)-ABDP complex could provide only a value of $g_{a v}$ and gave no hint about the individual $g_{x}, g_{y}, g_{z}$ or $g_{\perp}$ and $g_{\perp}$ values. It has been suggested that the value other than an isotropic $g$-values from the powdered spectrum cannot be assigned ${ }^{42}$. From the spectrum, considerable interaction between the copper(II) centers can be interpreted and also that it is antiferromagnetic. The $g_{a v}$ value (2.154) favours the presence of tetragonal distortion ${ }^{43}$.

EPR measurements have been made using a powdered sample of copper(II)-ACEDP complex, which could provide only a value of $\mathrm{g}_{\mathrm{av}}$ and does not give any hint about the individual $\mathrm{g}_{\Perp}$ and $\mathrm{g}_{1}$ values. The $\mathrm{g}_{\mathrm{av}}-$ value of the $\mathrm{cu}_{5}(\mathrm{~L})_{2} \cdot 4 \mathrm{H}_{2} \mathrm{O}$ complex was calculated to be 2.13 which deviates slightly from the free spin value. This deviation may be due to the covalent bonding. The $\mathrm{g}_{\mathrm{av}}$ value also supports a tetragonally distorted structure as has also been suggested by Low ${ }^{43}$. 
EPR spectrum of $\mathrm{Cu}_{4}$ (L). $6 \mathrm{H}_{2} \mathrm{O}$ (Copper(II)-DAPTP complex) has been studied. Only $\mathrm{g}_{\mathrm{av}}$ value could be calculated from the spectrum of the powdered sample. The $\mathrm{g}_{\mathrm{av}}$ value has been found to be 2.061. The deviation from the free-spin value may be due to covalent bonding and the $\mathrm{g}_{\mathrm{av}}$ value supports the presence of tetragonal distortion and antiferromagnetic behaviour.

The copper(II)-EDBDMPO complex shows typical axial spectrum suggesting a distorted octahedral structure. The $\mathrm{g}_{\mathrm{av}}$ - value of the $\mathrm{Cu}_{2}$ (EDBDMPO). $2 \mathrm{H}_{2} \mathrm{O}$ complex is 2.1096, which deviates slightly from the spin-free value. This deviation of $\mathrm{g}_{\mathrm{av}}-$ value also supports the presence of a tetragonal distortion ${ }^{43}$.

The $g_{a v}$ value of copper(II) - PDBDMPO complex has been found to be 2.1156 which deviates slightly from the free-spin value indicating that the ground state is not exactly ${ }^{2} \mathrm{D}_{5 / 2}$. This may be attributed due to the covalent bonding and favours the presence of a tetragonal distortion.

Powdered EPR spectrum of Cu L. $4 \mathrm{H}_{2} \mathrm{O}$ (Copper(II) DETBDMPO Complex) has been taken and discussed. EPR spectrum of copper(II) complex could provide only $\mathrm{g}_{\mathrm{av}}$ value of 2.11, which suggested the tetragonal distortion ${ }^{43}$ in the geometry ${ }^{22}$.

\section{Thermal analyses}

Thermal analysis of copper(II) HEDP complex (Figure $1 \& 2$ ) shows that it is stable only up to $40{ }^{\circ} \mathrm{C}$. It loses water molecules in two distinct steps in temperature ranges of $120-155^{\circ}$ and $160-195{ }^{\circ} \mathrm{C}$ The total mass loss corresponding to these two steps is 5.9 and $12.0 \%$ respectively (theoretical loss, required for one molecule of water being 5.9 and two water molecules $11.8 \%$ respectively). The DTA curve shows a corresponding endothermic peak with minima at $140{ }^{\circ} \mathrm{C}$ and an inflection at $190{ }^{\circ} \mathrm{C}$. The third step in the temperature range 230-280 ${ }^{0} \mathrm{C}$ seems to be the decomposition of organic part of the molecule with exothermic effect at $270{ }^{\circ} \mathrm{C}$. The next exothermic maxima at $350{ }^{\circ} \mathrm{C}$ is accompanied by $1.5 \%$ increases in weight probably due to oxidation of the compound. Weight is again lost which may be due to the removal of carbon dioxide and water formed during the reaction. The final products appear to be CuO. $\mathrm{P}_{2} \mathrm{O}_{5}$. The total theoretical loss is $27.0 \%$, experimental being $27.01 \%$. (Figure 1)

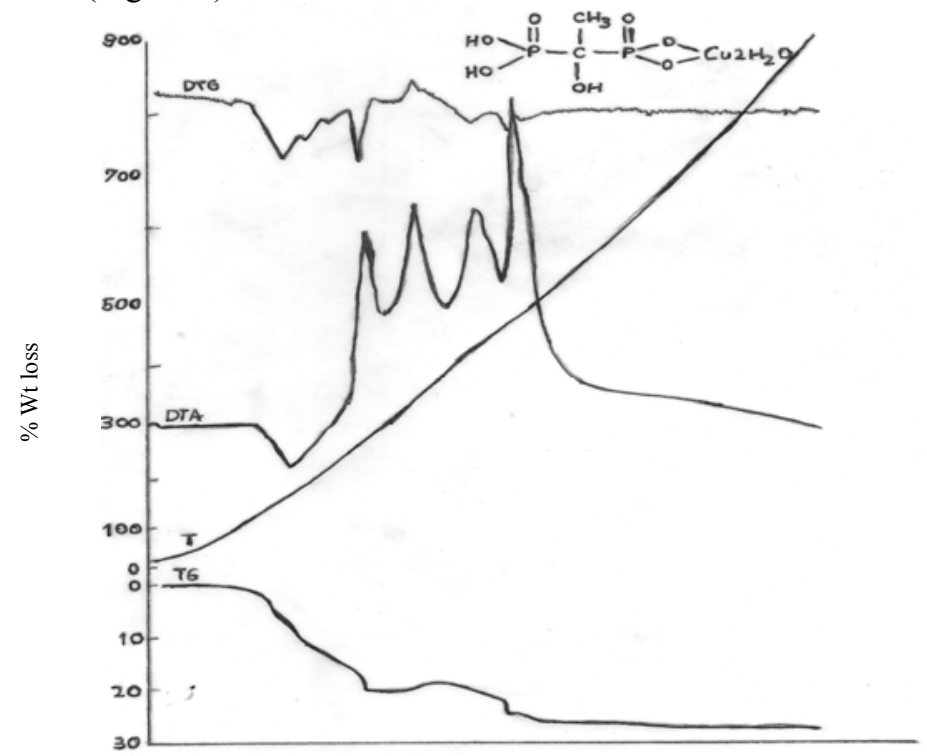

Figure 1. Derivatogram of Cu-HEDP- $2 \mathrm{H}_{2} \mathrm{O}$ (100 mg specimen) 


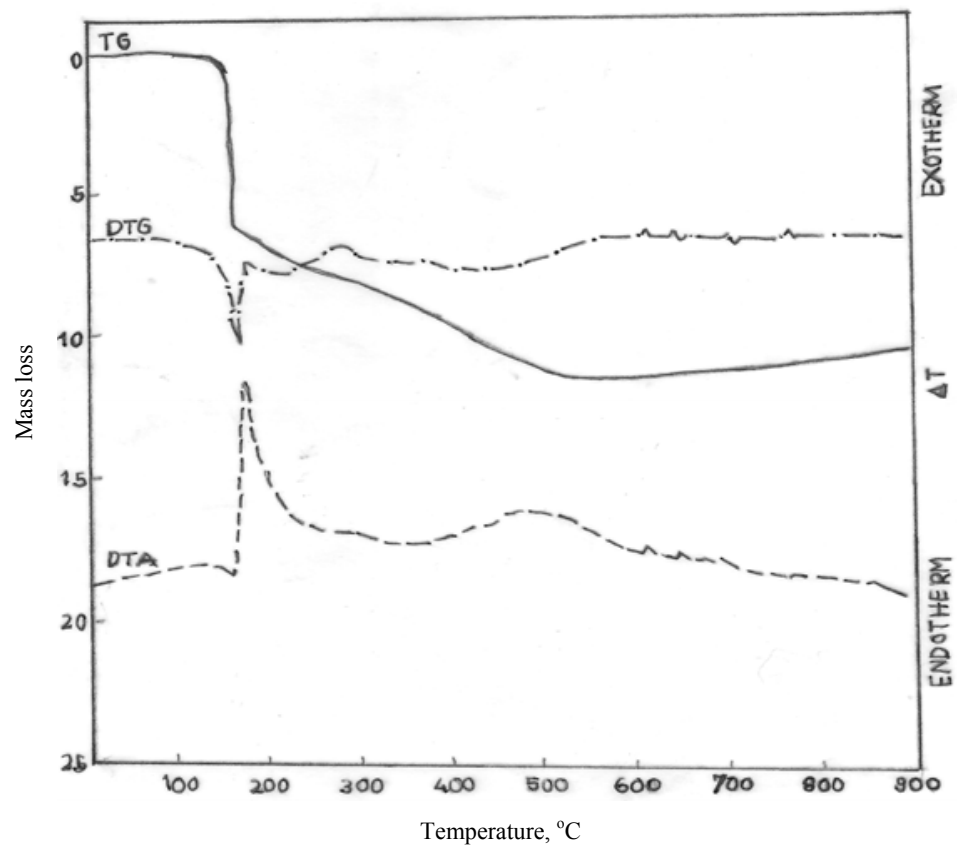

Figure 2. Thermoanalytical curves of $\mathrm{Cu}_{5}\left(\mathrm{C}_{3} \mathrm{H}_{4} \mathrm{NO}_{8} \mathrm{P}_{2}\right)_{2} 4 . \mathrm{H}_{2} \mathrm{O}$ (200 mg specimen)

In thermal analysis of copper(II) ACEDP complex, the first endothermic effect at $160{ }^{\circ} \mathrm{C}$ on the DTA curve corresponds to the loss of four water molecules. The second endothermic effect at $220{ }^{\circ} \mathrm{C}$ showed the loss of two $\mathrm{NH}_{3}$ and two $\mathrm{CO}_{2}$ molecules. The total mass loss $(23 \%)$ indicates that the final product is found to be $\mathrm{CuO} \cdot \mathrm{P}_{2} \mathrm{O}_{5}$. (Theoretical mass loss, 24.04\%) (Figure 2)

\section{Conclusion}

All these complexes were insoluble in water as well as other common organic solvents and did not melt even up to $270-280{ }^{\circ} \mathrm{C}$. The properties indicated them to be polymeric in nature. Polymeric nature has also been established based on phosphoryl oxygen coordinated to metal atom, which is assigned from the I.R data of metal derivatives. Stereochemistry of complexes were found to have hexa-coordinated and distorted octahedral geometry.

ESR spectral study of some of the copper(II) complexes has been made and from this, these compounds have been found to be tetragonally distorted. The magnetic moments of the complexes have been found to be subnormal at room temperature. These low magnetic moment values may be due to the presence of antiferromagnetism which can arise due to polymeric nature of the complexes and thus bring the metal ions at distance close enough to interact or through super exchange via phosphonic acid or hydroxo bridges (in case of trivalent metal compounds). The magnetic moments have decreased with decreasing temperature. A straight line was obtained when $1 / \chi$ ' $\mathrm{M}$ was plotted against temperature. Curie-Weiss law is also obeyed with the $\theta$ values ranging from 77 to $-297 \mathrm{k}$.

Thermal behaviour (TG, DTA and DTG) of some of the complexes of different series showed thermal degradation pattern and can be represented schematically as follows:

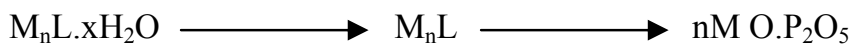




\section{Acknowledgment}

Thanks are due to C.S.I.R fellowship to Dr.B.V.R. Thanks is also due to Management of ALC for encouragement.

\section{References}

1. Blaser B. Von, Worms K H, Germscheid H G and Wollmann K, Z Anorg Allg Chem., 1971, 381, 247; Chem. Abstr., 1971, 75, 36247y.

2. Kabachnik M I, Medved T Ya, Dyatlova N M and Rudomino M V, Russian Chem. Revs., 1974, 43(9), 733-744.

3. Zhadanov B V and Dyatlova N M, Russ J Phys Chem., 1969, 43(3), 409, 744.

4. Cotton, F.A and Wilkinson, Advanced Inorganic Chemistry, Wiley Eastern, New Delhi, 1969, pp 538, 825,836,841,860.

5. Willet R D, J Chem Phys., 1964, 41, 2243.

6. Goodgame D M L and Goodgame M, and Cotton F A, J Chem Soc., 1961, 2298.

7. Wekher F J., The Analytical uses of Ethylenediaminetetraacetic acid, Van Nostrand D Company Inc., New York, 1958, p.3.

8. Corbridge D E C, Topics in Phosphorus Chemistry, Interscience Publishers, New York, Edited by Crayson M and Griffith E J, 1969, 6, 235.

9. Kabachnik M I., Medved T Ya, Dyatlova N M, Arkhipova O G and Rudomino M V, Russ Chem Rev., 1968, 37(7), 503-518.

10. Zablotna R, Zylicz E, Szot Z, Peskorska C, Anna G, Nukleonika, 1977, 22(8), 703-11.

11. Ploger W, Schindler N, Wollmann K and Woras K N, Z Anorg Allg Chem., 1972,119, 389.

12. Lerch I. and Kottler A, Ger Pat., 1957, 1,002,355, Feb.14; Chem Abstr., 1959, 53, 21814c.

13. Medved T Ya, Rudomino M V, Mironova E A, Bala Bukha V S and Kabachnik M I, Izv Akad Nauk Ser Khim., 1967, 37(7) 351-6 (Russ).

14. Vogel A I, A Text book of Quantitative Inorganic Analysis, $7^{\text {th }}$ Edn., (Longman, London), 1996.

15. Palta N, Rao B V, Dubey S N and Puri D M, Indian J Chem., 1984, 23A, 397.

16. Palta N, Rao B V, Dubey S N and Puri D.M, Polyhedron., 1984, $\underline{3}, 527$.

17. Puri D M and Neelam Palta, Indian J Chem., 1982, 21A, 624.

18. Khramov V P and Kol'tsov A.A, Russ J Inorg Chem., 1973, 18(11), 1567; a) Zurowska B, Mrozinski J and Ochocki J, Mater Sci Poland, 2007, 25(4), 1063-1074;

19. Scheinmann (Editor), An Introduction to Spectroscopy Methods for the Identification of Organic compounds, Pergamon Press, 1970; Fujita J, Nakamoto K. and Kobayashi M, J Am Chem Soc., 1956, 78, 3963.

20. Patel M M and Patel R P, J Indian Chem Soc., 1975, 52, 1046.

21. Shukla P R, Singh V K, Jaiswal A M and Narayan G, J Indian Chem Soc., 1983, 60, 321.

22. Abraham A and Bleaney B, Electron Paramagnetic Resonance of Transition Metal ions, Clarendon press, Oxford, 1970.

23. Delvin B R J, (Shell International Research Maats Chappis B.V.), Brit., 11,508, 772, (c, AO1N 9136), 26 Apr. 1978, Appl. 74115,255, 05 Apr. 1974; 15 pp; Chem Abstr., $1979,90,34989 \mathrm{e}$.

24. a) Sengupta S K, Sahni S K and Kapoor R N, Polyhedron, 1983, 2, 317;

b) Maurya R C, Chourasia J and Sharma P, Indian J Chem., 2007, 46A, 1594-1604;

c) Maurya R C, Sharma P and Sutra Dhar D, Synth React Inorg Met Org Chem., 2003, 33, 669. 
25. Dyer J R, Applications of Absorption Spectroscopy of Organic Compounds, Prentice Hall of India, New Delhi, 1978, p.37.

26. Lever A B P, Inorganic Electronic Spectroscopy, $2^{\text {nd }}$ Edn., (Elsevier Publ. Co., Amsterdam) 1984.

27. Lave L W and Taylor L J, J Coord Chem., 1973, 2, 295.

28. Rana A.K and Shah J R, Indian J Chem., 1981, 20A, 142.

29. Agambar C.A. and Orrell K G, J Chem Soc., 1969, 897.

30. Aggarwal R.C, Bala. R and Prasad R L, Indian J Chem., 1983, 22A, 955, Chakrabarty J and Sahoo B, Indian J Chem., 1982, 21A, 48.

31. a) Dianzhong F and Bo W, Trans Met Chem., 1993, 18, 101-103; b) Dutta R.L and Syamal A, Elements of Magnetochemistry, $2^{\text {nd }}$ Edn., (Affiliated East-West Press Pvt.Ltd., New Delhi) 1993, p.57, 107.

32. Kettle S F A and Pioli A J P, J Chem Soc., 1968, 1243.

33. Tsuchida R, Yamada S and Nakamura H, Nature, 1958, 181, 479.

34. Sanyal G S, Modak A.B and Mubi A K, Indian J Chem., 1982, 21A, 1044.

35. Barrow G M, Krueger R H and Basolo F, J Inorg Nucl Chem., 1956, 2,340 .

36. Figgis B N and Lewis J, Progress in Inorganic Chemistry, Edited by Cotton F A, Interscience Publishers, John Wiley and Sons, 1964, 6, p.96.

37. Michinoba K, Jonassen H B and Funning J C, Chem Rev., 1964, 64, 99.

38. Kiriyama R, Ibamoto H and Matsuo K, Acta Cryst., 1954, 7, 482-483.

39. Ranbore V, Tyagaraju V T, Atre V and Ganorkar M.C, Indian J Chem., 1982, 21A, 532-534.

40. Figgis B N, Introduction to Ligand Fields, Wiley Eastern, New Delhi, 1966.

41. Manhas B S, Kalia S B, Sardana A.K and Kaushal G, Indian J Chem., 2005, 44(8)A, 1576-1581.

42. Dubey R K and Mishra C M, Indian J Cem., 2008, 47A, 1208.

43. Low W, Paramagnetic Resonance in solids, Suppl 2, in: Solid State Physics, Academic Press, New York and London, 1960, 2, 92. 


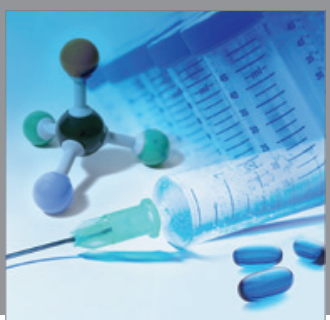

International Journal of

Medicinal Chemistry

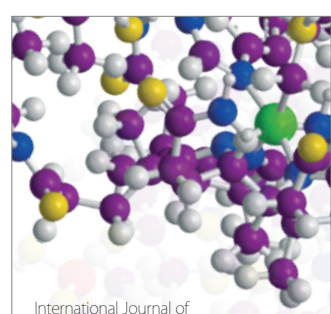

Carbohydrate Chemistry

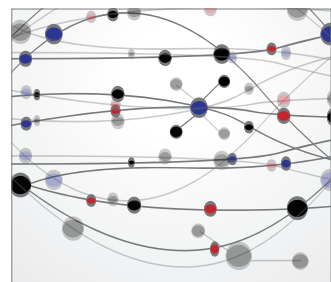

The Scientific World Journal
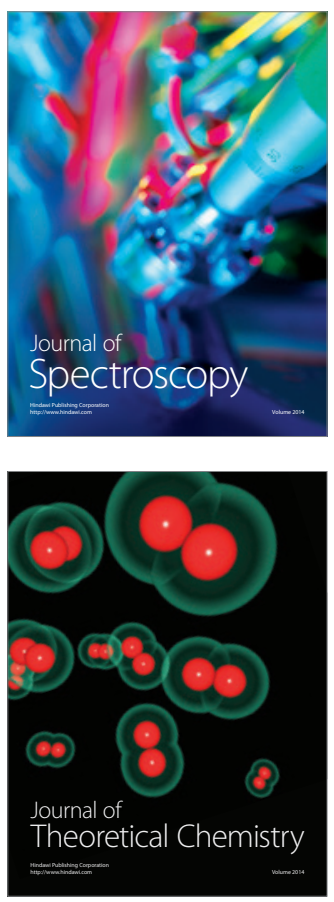
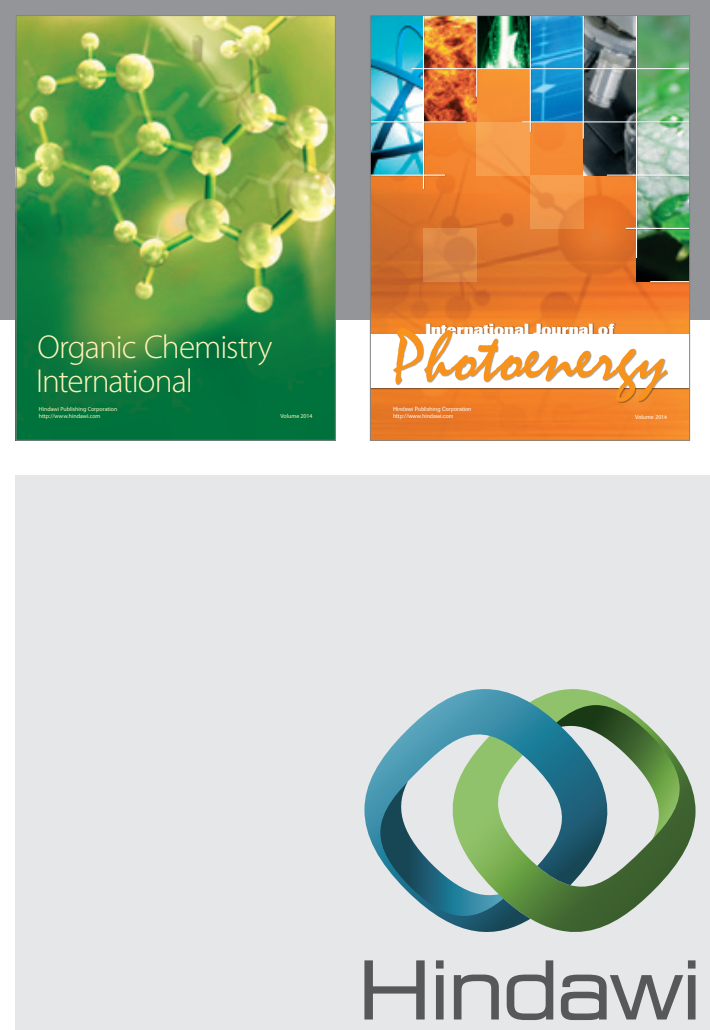

Submit your manuscripts at

http://www.hindawi.com
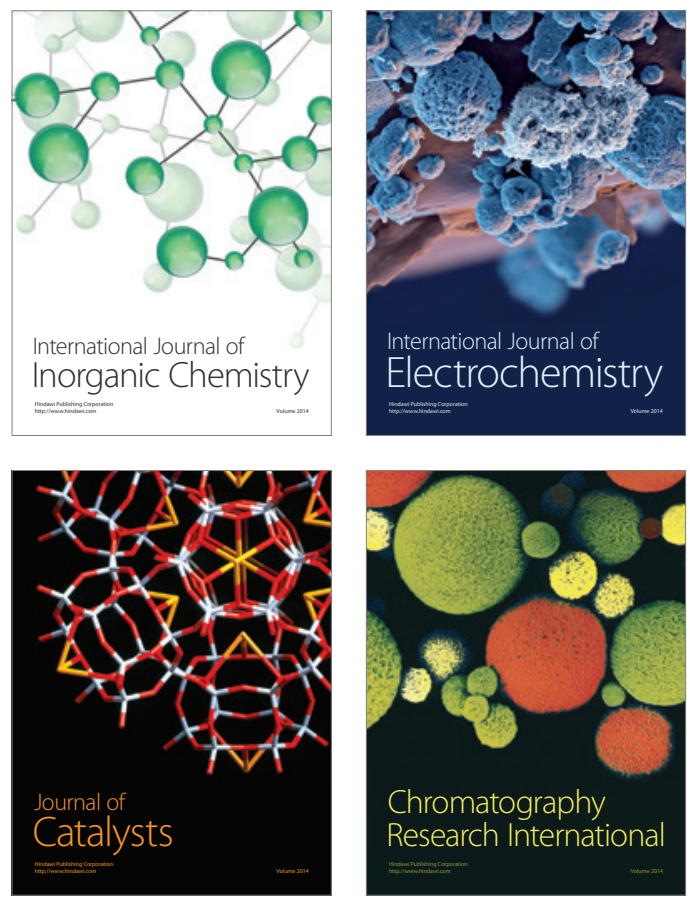
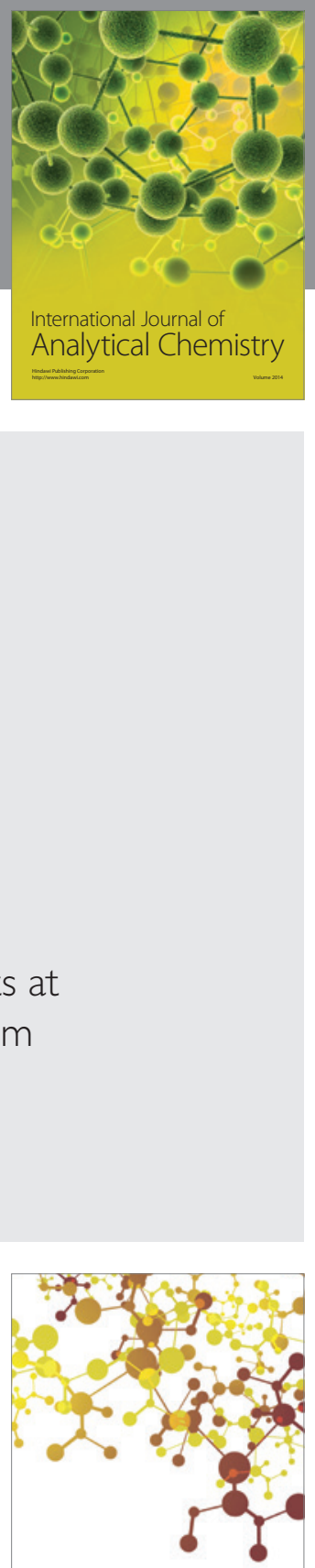

Journal of

Applied Chemistry
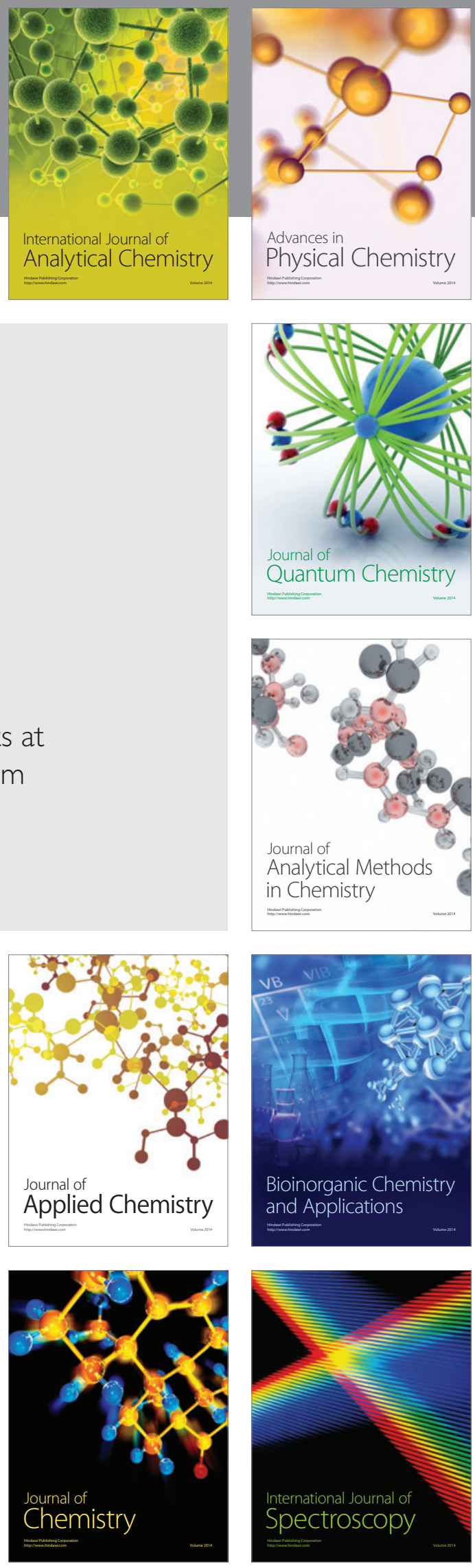